\title{
Analysis of 13 million individual patient records pertaining to Pap smears, colposcopies, biopsies and surgery on the uterine cervix (Belgium, 1996-2000)
}

\author{
Marc Arbyn a,b,*, Cindy Simoens a , Herman Van Oyen ${ }^{c}$, Jean-Michel Foidart ${ }^{\mathrm{d}}$, Frédéric Goffin ${ }^{\mathrm{d}}$, \\ Philippe Simon ${ }^{\mathrm{e}}$, Valérie Fabri ${ }^{\mathrm{f}}$ \\ a Belgian Cancer Center/Unit of Cancer Epidemiology, Scientific Institute of Public Health, J. Wytsman Street 14, B 1050 Brussels, Belgium \\ ${ }^{\mathrm{b}}$ European Network for Information in Cancer Epidemiology, IARC, Lyon, France \\ c Department of Cancer Epidemiology, Scientific Institute of Public Health, Belgium \\ d Department of Gynecology and Obstetrics, University of Liège, Liège, Belgium \\ e Service de Gynecologie-Obstetrique, Hopital Erasme, Bruxelles, Belgium \\ ${ }^{\mathrm{f}}$ Intermutualistic Agency (IMA/AIM), Brussels, Belgium
}

\section{A R T I C L E I N F O}

Available online xxxx

\section{Keywords:}

Cervical cancer screening

Pap smear

Screening coverage

Colposcopy

Conization

Hysterectomy

Belgium

\section{A B S T R A C T}

Objective. Cervical cancer screening by surveys overestimate coverage because of selection and reporting biases.

Methods. The prepared Inter-Mutualistic Agency dataset has about 13 million records from Pap smears, colposcopies, cervical biopsies and surgery, performed in Belgium between 1996 and 2000. Cervical cancer screening coverage was defined as the proportion of the target population (women of 25-64 years) that has had a Pap smear taken within the last 3 years. Proportions and incidence rates were computed using official population data of the corresponding age group, area and calendar year.

Results. Cervical cancer screening coverage, in the period 1998-2000, was 59\% at national level, for the target age group 25-64 years. Differences were small between the 3 regions. Variation ranged from $39 \%$ to $71 \%$. Coverage was $64 \%$ for $25-29$ year old women, $67 \%$ for those aged $30-39$ years, $56 \%$ for those aged $50-54$. The modal screening interval was 1 year. In the 3-year period 1998-2000, 3 million smears were taken from the 2.7 million women in the age group 25-64. Only 1.6 million women of the target group got one or more smears in that period and 1.1 million women had no smears, corresponding to an average of 1.88 smears per woman.

Conclusion. Coverage reached only 59\%, but the number of smears used was sufficient to cover more than $100 \%$ of the target population. Structural reduction of overuse and extension of coverage is warranted.

(C) 2009 Elsevier Inc. All rights reserved.

\section{Introduction}

The Belgian Cancer Registry (Belgian Cancer Registry Foundation, 2008 ) records yearly, approximately 650 to 700 cases of invasive cervical cancer and between 290 and 370 women die from the disease (Arbyn and Geys, 2002; Arbyn et al., 2007, in press-b). The burden of cervical cancer in Belgium ranks at a central place among the member states in the European Union with a world-age standardized incidence and mortality rate of 11 and 4/100 000 women-years, respectively (Arbyn et al., 2007).

Through a well-organized cytological screening, the incidence of cervical cancer can be reduced to a small residual level (IARC, 2005), as was demonstrated two decades ago in four Nordic countries (Laara et al., 1987) and more recently in the United Kingdom (Quinn et al., 1999; Peto et al., 2004), Norway (Nygard et al., 2002), and the Netherlands (van der Aa et al., 2007). In Belgium, screening is essentially opportunistic, which means that Pap smears are taken at the

\footnotetext{
* Corresponding author.

E-mail address: marc.arbyn@iph.fgov.be (M. Arbyn).
}

spontaneous initiative of the woman, her gynecologist or her general practitioner (Arbyn and Van Oyen, 2004; Arbyn et al., in press-a). Opportunistic screening usually results in a high level of overscreening and a heterogeneous quality (Miller, 2002; Arbyn et al., in press-c). In spite of the large amount of Pap smears consumed yearly, the impact on cervical cancer mortality was lower than observed in the organized Nordic countries (Arbyn et al., 2002; Arbyn and Geys, 2002).

The Belgian cervical cancer screening policy is adapted from the European Guidelines and foresees one Pap smear or liquid-based cytology sample every 3 years for women of 25 to 64 years of age (Coleman et al., 1993; Council of the European Union, 2003; European Commission, 2008). Nevertheless, the level of adherence to this policy is rather poor, also in the Flemish provinces where in the mid 1990s, a program was set up involving invitation of women in the target age range 25-64 (Arbyn et al., in press-a).

Optimal attendance of the target population is one of the main determinants of success of a screening program (Anttila et al., 2008). Until recently, in Belgium, this attendance could only be assessed by surveys (Arbyn et al., 1997; Arbyn and Van Oyen, 2000; Demarest et al., 2002). Such surveys, involving collection of information directly from 
Cytological screening for cervical cancer Belgium, 2000

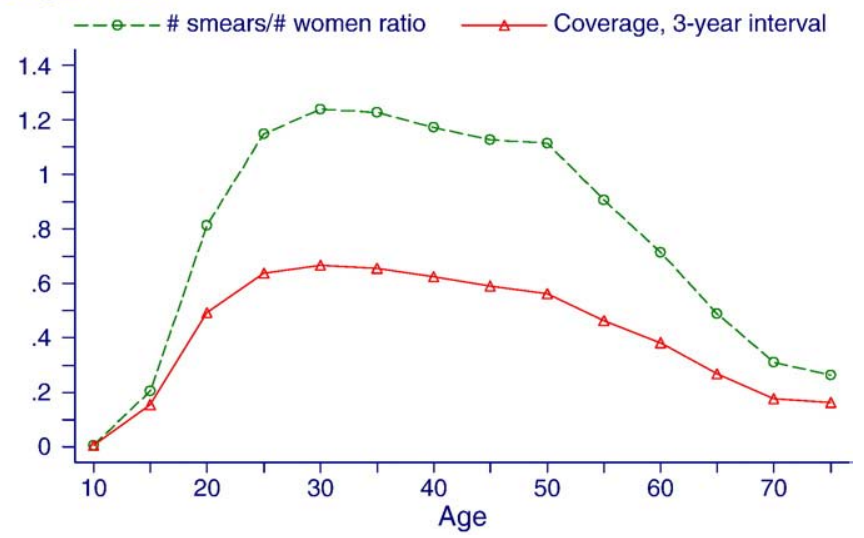

Fig. 1. Variation of the screening coverage and the \# smears/\# women ratio considered over a 3-year interval according to 5-year age group (Belgium, 2000).

women, are known to suffer from selection and reporting biases that systematically result in overestimated coverage rates (Kottke et al., 1995; Montano and Phillips, 1995). The current study aims to assess the real cytological screening coverage as well as the consumption of medical acts for screening and follow-up or treatment of screen positive women. Therefore, a data file obtained from the Inter-Mutualistic Agency (IMA), which pools information from all social health insurance companies in Belgium (Arbyn and Van Oyen, 2004), was used.

\section{Methods}

A mandatory social health insurance system covers the whole population, officially residing in Belgium. This health insurance system is mediated by "sickness funds" that register all reimbursed contacts of their members with health services. The Inter-Mutualistic Agency (IMA) compiles, for specific purposes, files from reimbursement claims originating from the sickness funds. This generates a virtually complete source of information on health services delivered to patients, since over $99.5 \%$ of the Belgian resident population is registered as having a health insurance. On demand of the Scientific Institute of Public Health (Brussels, Belgium), a data file containing more than 13 million individual patient records was compiled by IMA. It contained information of all medical acts related to cervical screening and diagnostic or therapeutic interventions on the uterine cervix (Pap smear collection and interpretation, colposcopies, cervical biopsies and their interpretation, surgery on the cervix) performed on women resident in Belgium, between 1996 and 2000. The database involves medical acts performed in all types of medical services (private physicians, group practices, private and public outpatient clinics and hospitals). The data set didn't contain diagnostic or clinical information.

A numerical individual ID code (to ensure privacy protection), age, date of the act, residence of the woman, and type of the medical act was provided in the data set. The ID code was a number which was constant at the level of the individual woman, allowing tracing of longitudinal histories. For all subjects, data details were truncated to reduce the risk of obtaining unique data in the cells of cross tables. Age was converted into five-year age groups at the exception of the group $0-14$ and the $75+$ age group, which were each grouped into one category. The calendar date of the act was restricted to the year of performance. The residence was converted into the district. The code 'district $=99$ ' was reserved for Belgian insured women, not residing in Belgium. Sometimes, district code $=0$ was used in case of rare combinations to avoid identification of women.

\section{Statistical analyses}

Data were aggregated by age groups, by several geographical levels (country, 3 regions [Flemish Region, Capital Region of Brussels, and the Walloon Region], 11 provinces and 43 districts), and combined with the respective mid-period population size (source: National Institute of Statistics) to compute proportions or incidence rates.

Cervical cancer screening coverage was defined as the proportion of the target population (women of 25-64 years) that has had a Pap smear taken within the last 3 years. Overuse (or excess use) was defined as the proportion of Pap smears taken in the target group that does not contribute to the coverage (number of smears taken in 3years time / number of women screened in that period -1$) * 100$.

For computation of cumulative incidence until a given age $k$, the following formula was applied:

$$
\text { Cumulative Incidence }=\prod_{k=1}^{k}\left(1-e^{a_{\mathrm{i}} \cdot \Delta T}\right),
$$

where $\Pi$ stands for cumulative product, $a_{\mathrm{i}}$ for age-specific incidence, and $\Delta T$ for the amplitude of the age categories (Kleinbaum et al., 1982).

\section{Results}

\section{Screening coverage}

Cervical cancer screening coverage, measured in 2000, was $59 \%$ (Fig. 1). The range of variation in screening coverage at the level of

Table 1

Consumption of Pap smears, associated costs (in euro), three-year screening coverage and overuse for women between 25 and 64 year old, by region (Belgium, 1996-2000).

\begin{tabular}{|c|c|c|c|c|c|c|c|}
\hline Region & Period & $\begin{array}{l}\text { Mean female population } \\
\text { (25-64 years) }\end{array}$ & $\begin{array}{l}\text { Number of } \\
\text { smears taken }\end{array}$ & $\begin{array}{l}\text { Number of women } \\
\text { screened }<3 \text { years ago }\end{array}$ & $\begin{array}{l}\text { 3-year } \\
\text { coverage }\end{array}$ & $\begin{array}{l}\text { \#smears/\#women } \\
\text { ratio }\end{array}$ & Excess use \\
\hline \multirow[t]{3}{*}{ Flemish Region } & 1996-1998 & $1,582,128$ & $1,569,687$ & 870,520 & $55.0 \%$ & 0.99 & $80.3 \%$ \\
\hline & 1997-1999 & $1,585,642$ & $1,639,685$ & 900,538 & $56.8 \%$ & 1.03 & $82.1 \%$ \\
\hline & $1998-2000$ & $1,587,847$ & $1,691,932$ & 911,761 & $57.4 \%$ & 1.07 & $85.6 \%$ \\
\hline \multirow[t]{3}{*}{ Brussels } & 1996-1998 & 253,557 & 264,611 & 134,397 & $53.0 \%$ & 1.04 & $96.9 \%$ \\
\hline & 1997-1999 & 254,534 & 277,884 & 141,204 & $55.5 \%$ & 1.09 & $96.8 \%$ \\
\hline & $1998-2000$ & 255,656 & 292,582 & 147,381 & $57.6 \%$ & 1.14 & $98.5 \%$ \\
\hline \multirow[t]{3}{*}{ Walloon Region } & 1996-1998 & 867,361 & 944,176 & 506,947 & $58.4 \%$ & 1.09 & $86.2 \%$ \\
\hline & 1997-1999 & 870,296 & 983,611 & 522,153 & $60.0 \%$ & 1.13 & $88.4 \%$ \\
\hline & $1998-2000$ & 873,429 & $1,010,866$ & 532,113 & $60.9 \%$ & 1.16 & $90.0 \%$ \\
\hline \multirow[t]{3}{*}{ Whole of Belgium } & 1996-1998 & $2,703,047$ & $2,778,474$ & $1,511,864$ & $55.9 \%$ & 1.03 & $83.8 \%$ \\
\hline & 1997-1999 & $2,710,473$ & $2,901,180$ & $1,563,895$ & $57.7 \%$ & 1.07 & $85.5 \%$ \\
\hline & $1998-2000$ & $2,716,933$ & $2,995,380$ & $1,591,255$ & $58.6 \%$ & 1.10 & $88.2 \%$ \\
\hline
\end{tabular}




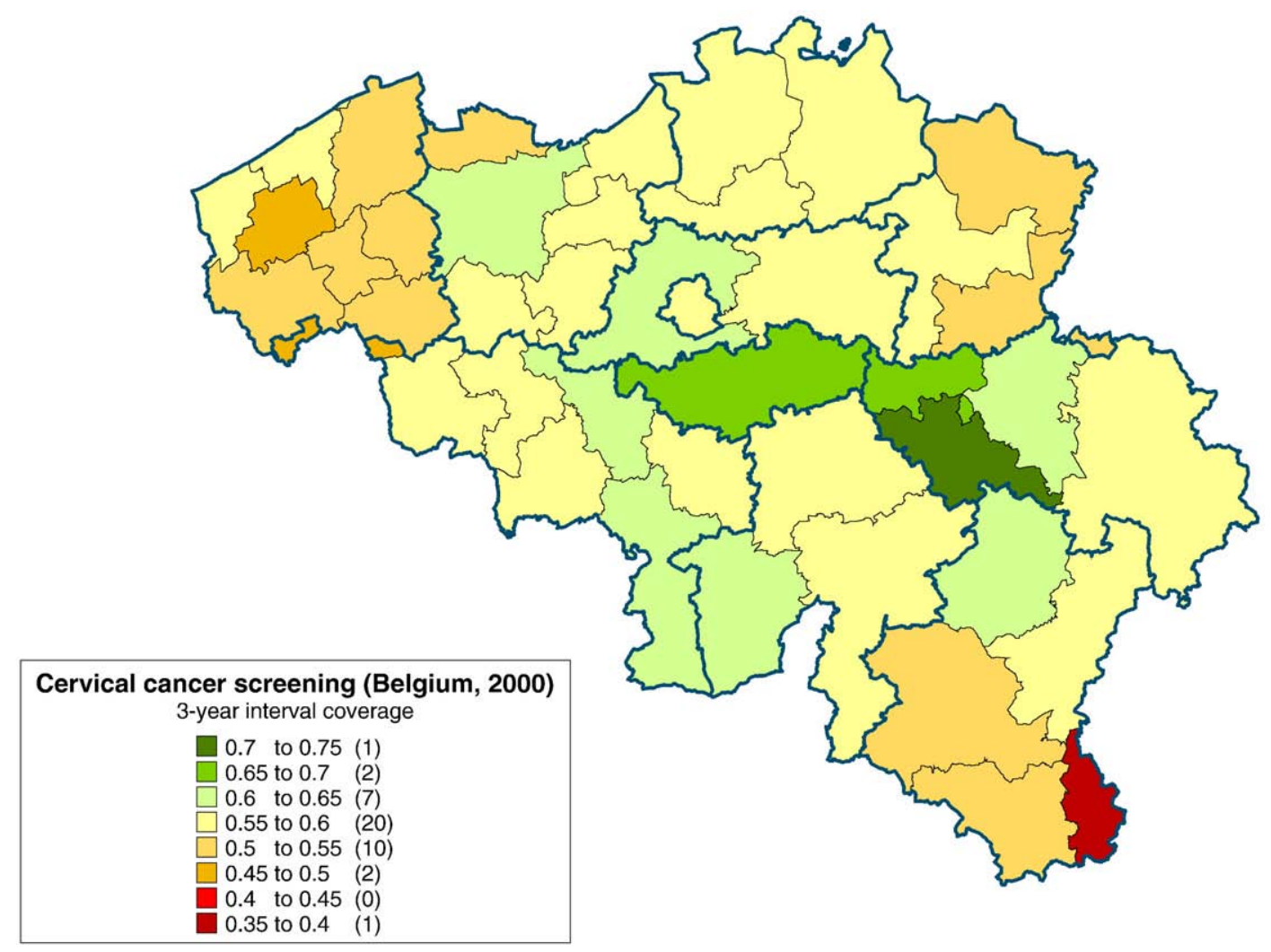

Fig. 2. Geographical variation of the screening coverage considered over a 3-year interval (Belgium, by District, 1998-2000, 25-64 years old women).

the Regions was small: $57 \%$ in the Flemish Region, 58\% in Brussels and $61 \%$ in the Walloon Region. The increase in coverage measured over the period 1996-2000 was limited and respectively 2\%, 5\% and $3 \%$ in the Flemish, Brussels and Walloon Region (Table 1). This limited increase in the Flemish Region was remarkable, given the fact that in this region a screening campaign was organized. Differences at lower geographical levels were substantial: at provincial level, in 2000, screening coverage ranged from 52\% (Luxembourg) to $69 \%$ (Walloon-Brabant); whereas at district level the highest coverage is found in Huy (71\%) and the lowest in Arlon (only 39\%) (Fig. 2).

In the youngest 5-year age group of the target population, women of 25-29 year old, the coverage was $64 \%$, at the national level. It increased until $67 \%$ among women in the age range 30 39 years. From the age of 40 , the coverage decreased gradually until $56 \%$ in the 50-54 year age group. Thereafter, the coverage declined more rapidly (Fig. 1). In the Brussels and Walloon Region this decline by age group was less pronounced.

\section{Screening interval and screening beyond the target age range}

For women contributing two or more smears, the screening intervals were less than 1 year in $13 \%, 1$ year in $61 \%$, 2 years in $21 \%$,
3 years in $5 \%$, and 4 years or more in $1 \%$. Ten percent of all interpreted Pap smears were taken from women younger than 25 years and $7 \%$ in women older than 64 years. In younger women, the three-year screening coverage was $16 \%$ and $49 \%$, for the age groups $15-19$ and $20-24$, respectively. For older women, the coverage was $27 \%$ in the age group 65-69 and 18\% in the age group 70-74.

\section{Profession of smear takers}

The large majority of smears were taken by gynecologists (85\%). The proportion of smears prepared by general practitioners (GPs) was limited (15\%) and varied substantially by Region: in 2000, in the Flemish Region 20\% was taken by GPs, whereas only $8 \%$ and $3 \%$ in Brussels and the Walloon Region respectively. The trend of the proportion of cervical samples collected by GPs was decreasing between 1996 and 2000: $-22 \%,-19 \%$, and $-27 \%$ in the Flemish, Brussels, and Walloon Region, respectively.

\section{Pap smear use}

In 2000, the ratio of the number of Pap smear interpretations over the size of the target population concerned was 1.1. This ratio could have been higher if we would have been able to adjust the

Table 2

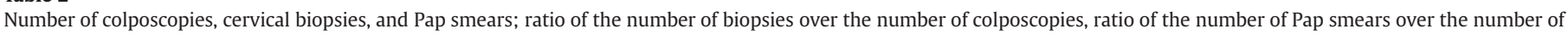
colposcopies, and ratio of the number of biopsies over the number of Paps, Belgium, 1996-2000.

\begin{tabular}{|c|c|c|c|c|c|c|}
\hline Region & Colposcopies & Biopsies & Pap smears & Biopsy/colposcopy ratio & Pap/colposcopy ratio & Biopsy/Pap ratio \\
\hline Flemish Region & 618,033 & 53,825 & $3,003,722$ & $8.7 \%$ & 4.9 & $1.8 \%$ \\
\hline Brussels & 207,587 & 12,143 & 586,105 & $5.8 \%$ & 2.8 & $2.1 \%$ \\
\hline Walloon Region & $1,176,139$ & 39,315 & $2,128,873$ & $3.3 \%$ & 1.8 & $1.8 \%$ \\
\hline Total & $2,001,759$ & 105,283 & $5,718,700$ & $5.3 \%$ & 2.9 & $1.8 \%$ \\
\hline
\end{tabular}



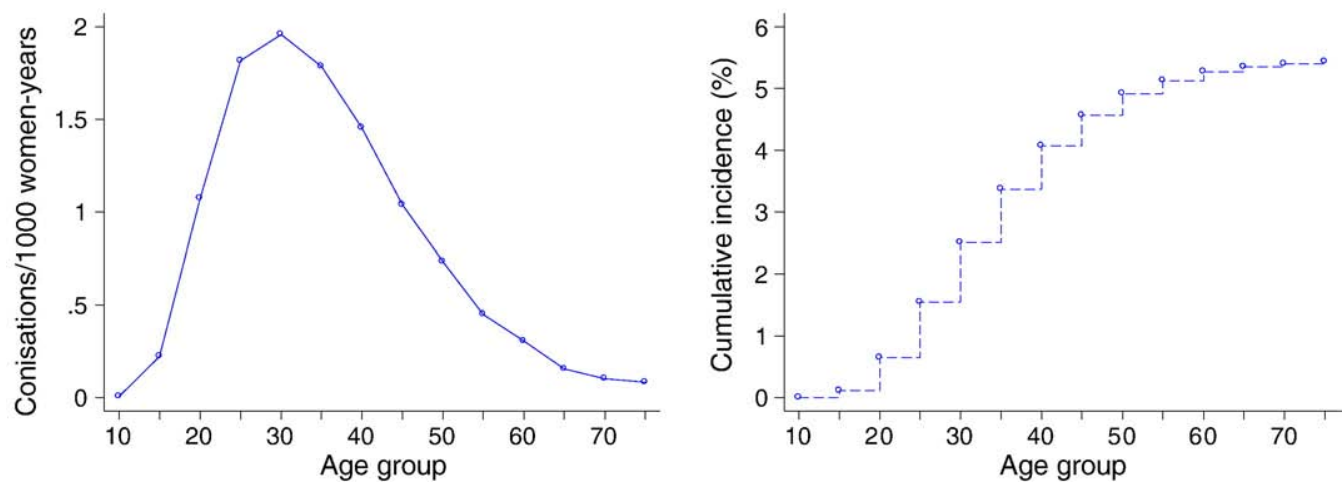

Fig. 3. Incidence of conization by age (left); cumulative incidence of conization up to a given age (right) in Belgium, 1996-2000.

size of the target population by excluding women whose cervix was removed before 1996. In absolute figures: 3 million Pap smears were interpreted in the period 1998-2000 which were taken from only 1.6 million women. One million and hundred thousand women, accounting for $41 \%$ of the target group, did not get a Pap smear during the study period. The excess use of cervical cytological examinations was $88 \%$, which means that each screened women received on average 1.88 smears over a 3 -year period. The excess smear use was high in all parts of Belgium: $86 \%$ in the Flemish Region, highest in the Capital Region (99\%), and intermediate in the Walloon Region (90\%) (Table 1).

\section{Colposcopy use}

At the national level, on average, one colposcopic examination was done for every 3 Pap smears. In the Flemish Region the ratio of the number of Pap smears over the number of colposcopies was 4.9, in Brussels 2.8, whereas for the Walloon Region this ratio was even less than two (Table 2). In some Walloon districts the number of examined Pap smears was equal to the number of performed colposcopies.

The biopsy/colposcopy ratio was low (on average 5\%), due to the very high frequency of colposcopy in cervical lesion free women (Table 2).

\section{Conizations}

Fig. 3 displays the incidence of conization (including large loop excision of the transformation zone (LLETZ)) by age, as well as the cumulative incidence up to a given age. Only first conizations were taken into account. The peak incidence was noted in the age group 3034 years (2.0/1000 women-years). Up to the age of 34 years, $2.5 \%$ of women have had a history of conization.

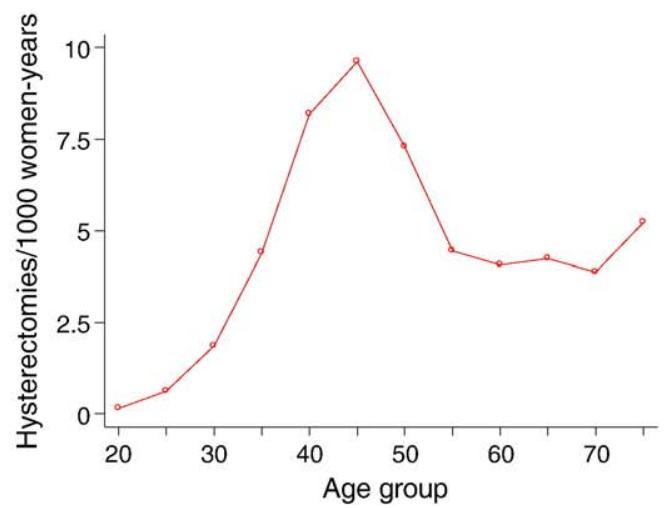

\section{Hysterectomies}

Fig. 4 displays the incidence of total hysterectomy by age, and the cumulative incidence up to a given age. The incidence of hysterectomy was highest in the age range $40-54$ years: $8.2,9.6$, and 7.3 per 1000 women-years in age groups $40-44,45-49$, and $50-54$ years, respectively. Up to the age of 49 years, $14.8 \%$ of women were hysterectomized. The shape of the curve was similar for the three regions as described for the whole of Belgium. However, the age-specific incidences were substantially higher in the Flemish Region and substantially lower in Brussels, compared to the national average. Peak incidences, in the 45-49 year age group were 10.6, 6.4, and 8.7 per 1000 women-years in the Flemish, Brussels Capital and Walloon Region, respectively.

Twenty five percent of women of 20 years or older, hysterectomized in 1997, had at least one Pap smear taken in the subsequent 3 years.

\section{Discussion}

The large exhaustive data file containing more than 13 million individual records compiled from reimbursement claims has, for the first time, enabled us to compute with high precision, the volume of performed medical acts that pertain to cervical cancer prevention.

\section{Screening coverage, amount and cost of over-screening}

Only $59 \%$ of women in the age range $25-64$ years had received a Pap smear in the last 3 years. However, the amount of smears taken should be sufficient to cover the whole target population. Indeed, assuming that $10 \%$ of the non-screening smears were spent for repeat

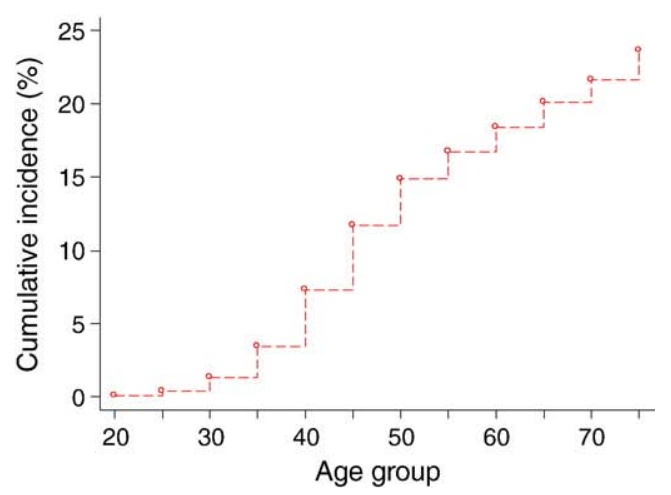

Fig. 4. Incidence of total hysterectomy by age (left); cumulative incidence of total hysterectomy up to a given age (right) in Belgium, 1996 -2000. 
smears because of prior cytological abnormalities or unsatisfactory specimen, for follow-up after negative colposcopy or after treatment of cervical lesions, we estimate that yearly about 400,000 Paps were taken that did not contribute to screening coverage or follow-up, for an estimated yearly budget of $€ 8.2$ million reimbursed by the National Health Insurance Institute. This amount is further increased by $€$ 3.9 million for screening performed beyond the target age range. Moreover, the costs for consultation by a gynecologist or GP were not taken into account in our analysis.

Most smears are taken by gynecologists. In the Walloon Region, the gynecologist is almost the exclusive smear taker. In a telephone survey conducted in the Flemish Region, in 1996, screened women indicated their gynecologist as the preferred smear taker, whereas nonscreened women would accept the proposal of a GP to have a Pap smear taken (Arbyn et al., 1997). These data show that GPs have a role to play in reaching non-covered women.

The coverage computed from the individual health insurance data file was substantially lower than the estimates derived from the national health interview surveys. For instance at national level, for the year 2000, this difference was 11\% (Demarest et al., 2002; Arbyn and Van Oyen, 2004). This discrepancy is probably due to reporting biases, which appear to be inherent to interview surveys (Walter et al., 1988; McKenna et al., 1992; Fruchter et al., 1992; Kottke et al., 1995; Montano and Phillips, 1995). Therefore, estimations of the screening coverage, derived from interview surveys should be interpreted with caution.

\section{Colposcopies}

An impressive amount of colposcopies are performed in Belgium. Colposcopy is often performed simultaneously to the Pap smear, whereas its main clinical indication is the exploration of women with previous cytological abnormality. It is clear that colposcopy was not used according to accepted national or international guidelines, considered in the study period (Kurman et al., 1994; Arbyn et al., 1996). In that period, colposcopic exploration was indicated in case of a first observation of HSIL (high-grade squamous intra-epithelial lesion) or glandular abnormality or after a second observation of ASCUS (atypiscal squamous cell of undermined significance) or LSIL (low-grade squamous intra-epithelial lesions). The prevalence of these lesions, estimated from reports received from laboratories in two Flemish provinces, was: $0.5 \%$ for HSIL, $1 \%$ for LSIL, $2 \%$ for ASCUS and $0.1 \%$ for atypical glandular cells (Arbyn et al., 1999a).

Health authorities and representatives of scientific societies should discuss as soon as possible on how to reduce the amount of colposcopies performed, the revalidation of its cost price, and the introduction of procedures of quality assurance.

\section{Conizations}

Over-consumption of screen tests, inevitably generates unnecessary follow-up examinations (repeat Pap smears, colposcopies, biopsies) and treatment of lesions. Recent meta-analytical work has indicated that excisional treatment of cervical intra-epithelial neoplasia (CIN) is associated with adverse obstetrical outcomes (Kyrgiou et al., 2006; Arbyn et al., 2008). Currently, LLETZ is the most frequently used procedure to treat CIN in Belgium as well as in other industrialized countries (Jordan et al., 2008; Wright et al., 2007). On average, pregnant women previously treated with LLETZ have a risk of preterm delivery (PD) that is 1.70 (95\% CI: 1.24-2.35) times higher than for non-treated pregnant women (Kyrgiou et al., 2006). Taking into account, the maternal age distribution at delivery (Centre for Operational Research in Public Health, 2006), and the cumulative incidence of conization over age (Fig. 3b), we can estimate that $2 \%$ (95\% CI: 0.7-3.6\%) of all PDs in Belgium are attributable to prior LLETZ.
However, among treated women, the risk of PD attributable to LLETZ is about 41\% (95\% CI: $19-57 \%)$.

\section{Hysterectomies}

Women who have undergone total hysterectomy are not at risk for cervical cancer if the indication for the intervention was not oncologic. These women could be excluded from the target population for cervical cancer screening. However, 25\% of women hysterectomized in 1997, had at least one Pap smear taken in the subsequent 3 years. From other sources, it was estimated that 13\% of total hysterectomies in Belgium are performed for a malignant indication (Mertens, 1999), so these women can be considered as still requiring cytological testing. Unfortunately, the data provided by IMA do not provide the indication of the hysterectomy. In a recent survey in the United States, it was noted that $64 \%$ of hysterectomized women were still cytologically screened (Sirovich and Welch, 2004). In Belgium, over-screening in women without cervix is dramatically lower.

\section{Study limitations}

The identities of the respective women were encoded to ensure protection of privacy. Nevertheless, records can refer to a unique person by their content when locality, age and date of the medical act are known. So, truncation of data was done to reduce the probability of providing unique data, which theoretically includes a risk of identifiability.

This impeded computation of precise screening intervals and excluded the possibility to assess the exact delay between (or the simultaneity of) Pap smear collection and other investigations or interventions.

The received data contained only administrative content and were not linkable with medical registries. It must be remarked that organized population screening, includes by definition registration of individual data with the possibility of linkage between population-, screening-, cancer- and mortality-registers (Council of the European Union, 2003; Commission of the European Communities, 2003). Moreover the Belgian privacy protection law foresees derogation specifically for population screening (Arbyn et al., 1999b).

\section{Conclusions}

The collected study material constitutes an enormous resource for epidemiological research and program evaluation. It reveals substantial overconsumption of resources with limited health benefits. The coverage reached only $59 \%$, but the number of smears taken was sufficient to cover more than $100 \%$ of the target population. Organized screening, involving a structural reduction of overuse and reinvestment in coverage and quality improvement, could potentially result in more life-years saved, without increase in public funding. Introduction of new methods, such as screening for oncogenic HPV (human papillomavirus) types and prophylactic HPV vaccination allowing screening at wider intervals and less aggressive management algorithms, a fortiori will require a well-organized screening system. Furthermore, public funding should be based upon evidence based recommendations, as described in the European Guidelines for cervical cancer screening.

\section{Conflict of interest statement}

The authors declare that there are no conflicts of interest.

\section{Acknowledgments}

We received financial support from (1) the European Commission (Directorate of SANCO, Luxembourg, Grand-Duché du Luxembourg), 
through the European Network for Information on Cancer (IARC, Lyon, France), (2) IWT (Institute for the Promotion of Innovation by Science and Technology in Flanders, project number 060081), (3) the Belgian Cancer Foundation, Brussels, Belgium, and (4) FNRS (le Fonds national de la Recherche Scientific), through TELEVIE, Brussels, Belgium (ref 7.4.628.07.F).

\section{References}

Anttila, A., Ronco, G., Lynge, E., et al., 2008. Chapter 2: epidemiological guidelines for quality assurance in cervical cancer screening, In: Arbyn, M., Anttila, A., Jordan, J., et al. (Eds.), European Guidelines for Quality Assurance in Cervical Cancer Screening, 2nd ed. Office for Official Publications of the European Communities, Luxembourg, pp. 11-52.

Arbyn, M., Geys, H., 2002. Trend of cervical cancer mortality in Belgium (1954-94): tentative solution for the certification problem of not specified uterine cancer. Int. J. Cancer 102, 649-654.

Arbyn, M., Van Oyen, H., 2000. Cervical cancer screening in Belgium. Eur. J. Cancer 36 2191-2197.

Arbyn, M., Van Oyen, H., 2004. Analysis of individual health insurance data pertaining to Pap smears, colposcopies, biopsies and surgery on the uterine cervix (Belgium, 19962000), 21. Scientific Institute of Public Health, Brussels, pp. 1-102. IPH/EPI-REPORTS.

Arbyn, M., Albertyn, G., De Groof, V., 1996. Consensus on follow-up recommendations in cervical cancer screening (in Dutch). Tijdschr voor Geneeskunde 52, 709-715.

Arbyn, M., Quataert, P., Van Hal, G., Van Oyen, H., 1997. Cervical cancer screening in the Flemish Region (Belgium): measurement of the attendance rate by telephone interview. Eur. J. Cancer Prev. 6, 389-398.

Arbyn, M., Bourgain, C., Cuvelier, C., et al., 1999a. The Flemish Cervical Cancer Screening Register: creation and first results. Acta Cytol 43, 708-709.

Arbyn, M., Wallyn, S., Van Oyen, H., Nys, H., Dhont, J., Seutin, B., 1999b. The new privacy law in Belgium: a legal basis for organised cancer screening. Eur. J. Health Law 6, 401-407.

Arbyn, M., Van Oyen, H., Sartor, F., Tibaldi, F., Molenberghs, G., 2002. Description of the influence of age, period and cohort effects on cervical cancer mortality by loglinear Poisson models (Belgium, 1955-94). Arch. Public Health 60, 73-100.

Arbyn, M., Raifu, A.O., Autier, P., Ferlay, J., 2007. Burden of cervical cancer in Europe: estimates for 2004. Ann. Oncol. 18, 1708-1715.

Arbyn, M., Kyrgiou, M., Simoens, C., et al., 2008. Peri-natal mortality and other severe adverse pregnancy outcomes associated with treatment of cervical intraepithelial neoplasia: a meta-analysis. BMJ 337, a1284.

Arbyn, M., Annemans, L., Vandenbroecke, A., in press-a. Screening for cervical cancer in Belgium. Eur. J. Cancer.

Arbyn, M., Raifu, A.O., Bray, F., Weiderpass, E., Anttila, A., in press-b. Trends of cervical cancer mortality in the member states of the European Union. Eur. J. Cancer.

Arbyn M., Rebolj M., de Kok I.M., Becker N., O'Reilly M., Andrae B., in press-c. Challenges for organising cervical screening programmes in the 15 old member states of the European Union. Eur. J. Cancer.

Belgian Cancer Registry Foundation, 2008. Belgian Cancer Registry.

Centre for Operational Research in Public Health, 2006. Standardised Procedures for Mortality Analysis. Scientific Institute of Public Health, Brussels.

Coleman, D., Day, N., Douglas, G., et al., 1993. European guidelines for quality assurance in cervical cancer screening. Europe against cancer programme. Eur. J. Cancer 4 (29A Suppl), S1-S38

Commission of the European Communities, Proposal for a council recommendation on cancer screening. 2003/0093 (CNS), 1-22. Brussels, 5th of May 2003.

Council of the European Union, 2003. Council recommendation of 2 December 2003 on cancer screening. Off. J. Eur. Union 878, 34-38.
Demarest, S., Van der Heyden, J., Gisle, L., et al., 2002. Health Survey by Interview, Belgium 2001, 25. Scientific Insitute of Public Health. IPH/EPI REPORTS, Brussels, pp. $1-2480$.

European Commission, 2008. European Guidelines for Quality Assurance in Cervical Cancer Screening, 2nd edn. Office for Official Publications of the European Communities, Luxembourg.

Fruchter, R.G., Rones, K., Roth, T., Webber, C.A., Camilien, L., Boyce, J.G., 1992. Pap smear histories in a medical clinic: accuracy of patients' self-reports. N. Y. State J. Med. 92 421-424.

IARC, 2005. Cervix cancer screening. IARC Handbooks of Cancer Prevention. Vol. 10 Lyon, IARCPress.

Jordan, J., Martin-Hirsch, P., Arbyn, M., et al., 2008. In: Arbyn, M., Anttila, A., Jordan, J. et al. (Eds.), Chapter 6: management of abnormal cervical cytology. In: European Guidelines for Quality Assurance in Cervical Cancer Screening, 2nd edn. Office for Official Publications of the European Communities, Luxembourg, pp. 191-232.

Kleinbaum, D.G., Kupper, L.L., Morgenstern, H., 1982. Epidemiologic Research: Principles and Quantitative Methods. Van Nostrand Reinhold, New York.

Kottke, T.E., Trapp, M.A., Fores, M.M., et al., 1995. Cancer screening behaviors and attitudes of women in southeastern Minnesota. JAMA 273, 1099-1105.

Kurman, R.J., Henson, D.E., Herbst, A.L., Noller, K.L., Schiffman, M.H., National Cance Institute, 1994. Interim guidelines for management of abnormal cervical cytology. JAMA 271, 1866-1869.

Kyrgiou, M., Koliopoulos, G., Martin-Hirsch, P., Arbyn, M., Prendiville, W., Paraskevaidis, E., 2006. Obstetric outcomes after conservative treatment for intra-epithelial or early invasive cervical lesions: a systematic review and meta-analysis of the literature. Lancet 367, 489-498.

Laara, E., Day, N.E., Hakama, M., 1987. Trends in mortality from cervical cancer in the Nordic countries: association with organised screening programmes. Lancet 1 1247-1249.

McKenna, M.T., Speers, M., Mallin, K., Warnecke, R., 1992. Agreement between patient self-reports and medical records for Pap smear histories. Am. J. Prev. Med. 8, 287-291.

Mertens, R., 1999. Hysterectomie in België. Thematic Files of the CSF, 1. National Alliance of the Christian Sickness Funds, Brussels, pp. 1-28.

Miller, A.B., 2002. The (in)efficiency of cervical screening in Europe. Eur. J. Cancer 38 $321-326$.

Montano, D.E., Phillips, W.R., 1995. Cancer screening by primary care physicians: a comparison of rates obtained from physician self-report, patient survey, and chart audit. Am. J. Public Health 85, 795-800.

Nygard, J.F., Skare, G.B., Thoresen, S.O., 2002. The cervical cancer screening programme in Norway, 1992-2000: changes in Pap smear coverage and incidence of cervical cancer. J. Med. Screen. 9, 86-91.

Peto, J., Gilham, C., Fletcher, O., Matthews, F.E., 2004. The cervical cancer epidemic that screening has prevented in the UK. Lancet 364, 249-256.

Quinn, M., Babb, P., Jones, J., 1999. Effect of screening on incidence and mortality from cancer of the cervix in England: evaluation based on routinely collected statistics. BMJ 318, 904-908.

Sirovich, B.E., Welch, H.G., 2004. Cervical cancer screening among women without a cervix. JAMA 291, 2990-2993.

van der Aa, M.A., Schutter, E.M., Looijen-Salamon, M., Martens, J.E., Siesling, S. 2007. Differences in screening history, tumour characteristics and survival between women with screen-detected versus not screen-detected cervical cancer in the east of The Netherlands, 1992-2001. Eur. J. Obstet. Gynecol. Reprod. Biol. 139, 204-209.

Walter, S.D., Clarke, E.A., Hatcher, J., Stitt, L.W., 1988. A comparison of physician and patient reports of Pap smear histories. J. Clin. Epidemiol. 41, 401-410.

Wright Jr., T.C., Massad, L.S., Dunton, C.J., Spitzer, M., Wilkinson, E.J., Solomon, D., 2007. 2006 consensus guidelines for the management of women with abnormal cervical cancer screening tests. Am. J. Obstet. Gynecol. 197, 346-355. 